LA-14444

Approved for public release;

distribution is unlimited.

\title{
CTH Simulation of PBX-9501 Taylor Tests
}


Los Alamos National Laboratory, an affirmative action/ equal opportunity employer, is operated by Los Alamos National Security, LLC, for the National Nuclear Security Administration of the U.S. Department of Energy under contract DE-AC52-06NA25396.

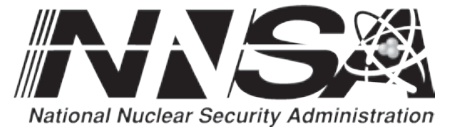

This report was prepared as an account of work sponsored by an agency of the U.S. Government. Neither Los Alamos National Security, LLC, the U.S. Government nor any agency thereof, nor any of their employees make any warranty, express or implied, or assume any legal liability or responsibility for the accuracy, completeness, or usefulness of any information, apparatus, product, or process disclosed, or represent that its use would not infringe privately owned rights. Reference herein to any specific commercial product, process, or service by trade name, trademark, manufacturer, or otherwise does not necessarily constitute or imply its endorsement, recommendation, or favoring by Los Alamos National Security, LLC, the U.S. Government, or any agency thereof. The views and opinions of authors expressed herein do not necessarily state or reflect those of Los Alamos National Security, LLC, the U.S. Government, or any agency thereof. Los Alamos National Laboratory strongly supports academic freedom and a researcher's right to publish; as an institution, however, the Laboratory does not endorse the viewpoint of a publication or guarantee its technical correctness. 
LA-14444

Issued: September 2011

CTH Simulation of PBX-9501 Taylor Tests

Joseph R. Koby

Los Alamos NATIONAL LABORATORY EST.1943 



\title{
CTH Simulation of PBX-9501 Taylor Tests
}

\author{
Joseph Koby
}

\begin{abstract}
During March-May 2011, multiple Taylor impact tests were conducted at LANL, examining the behavior of PBXN-9 and PBX-9501 under rapid loading. Subsequently, a computational hydrodynamics code (CTH) model was developed to mimic the deformation behavior observed in these impact tests with PBX-9501. Once suitably developed, additional simulations were performed with this model to determine the velocity range at which PBX-9501 would likely initiate upon impact. Also examined was whether an inert slug behind the explosive would lead to initiation at lower, more easily attainable velocities. The simplified model used here showed a minimum velocity for ignition of $530 \mathrm{~m} / \mathrm{s}$ which was unchanged by the addition of a plastic slug behind the sample. The use of a lead slug did lower the minimum velocity to $460 \mathrm{~m} / \mathrm{s}$. These values are likely more qualitative at this point because multiple simplifications are currently used in the materials properties and test geometry. The results do show that this approach is capable of determining ignition due to Taylor impact.
\end{abstract}

The model used for these simulations is a modified version of the steinberg.in input file supplied with CTH, which simulated a Taylor impact of a Tantalum cylinder. Modifications were made to the sample dimensions, mechanical and thermodynamic properties of the material, and impact velocity. All other parameters were essentially unchanged. The dimensions of the CTH material sample were made to match the dimensions of the real specimens used in the Taylor tests (cylinder with a diameter of $1.6 \mathrm{~cm}$, and a length of $7 \mathrm{~cm}$ ). The thermodynamic EOS selected for this simulation was the History Variable Reactive Burn (HVRB) model for PBX-9501, which is included in the CTH database. The HVRB model uses a pressure-dependent rate law for modeling the reaction of the energetic material being simulated, and triggers the reaction when a specified density or temperature is reached. Finally, the elastic-plastic properties consisted of a preset input for HTPB rubber, with the fracture parameters changed to favor crumbling behavior, as observed in PBX-9501. These parameters were used because CTH does not provide an elasticplastic model for PBX-9501 or its binders. 
Assorted pressure maps are shown for various velocities throughout this summary. At velocities too slow for initiation to occur, an impact wave can be seen propagating through the material, but no ignition occurs. The material subsequently deforms and breaks apart as the impact progresses. Velocities shown are $150 \mathrm{~m} / \mathrm{s}$ for Figure 1 and $500 \mathrm{~m} / \mathrm{s}$ for Figure 2. Despite the significant difference in velocity and consequent deformation rate, the qualitative behavior between the two tests is quite similar.
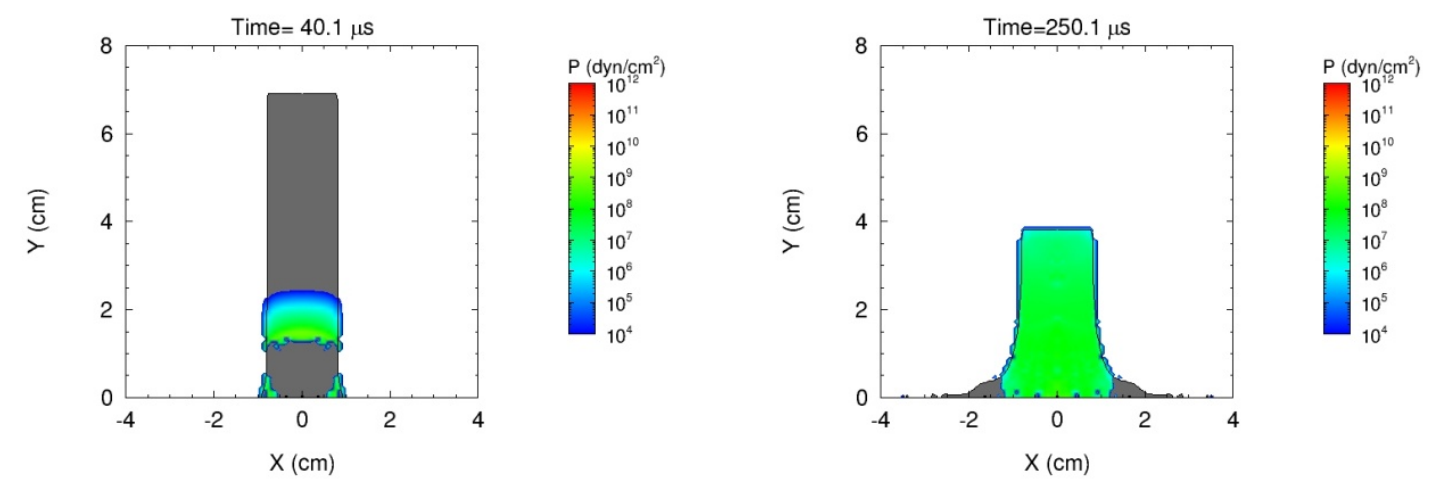

Fig 1. Impact profiles at $150 \mathrm{~m} / \mathrm{s}$, which is easily attainable with the Taylor gun in WX-7 at LANL. Pressure wave is visible in plot on left, taken shortly after impact.
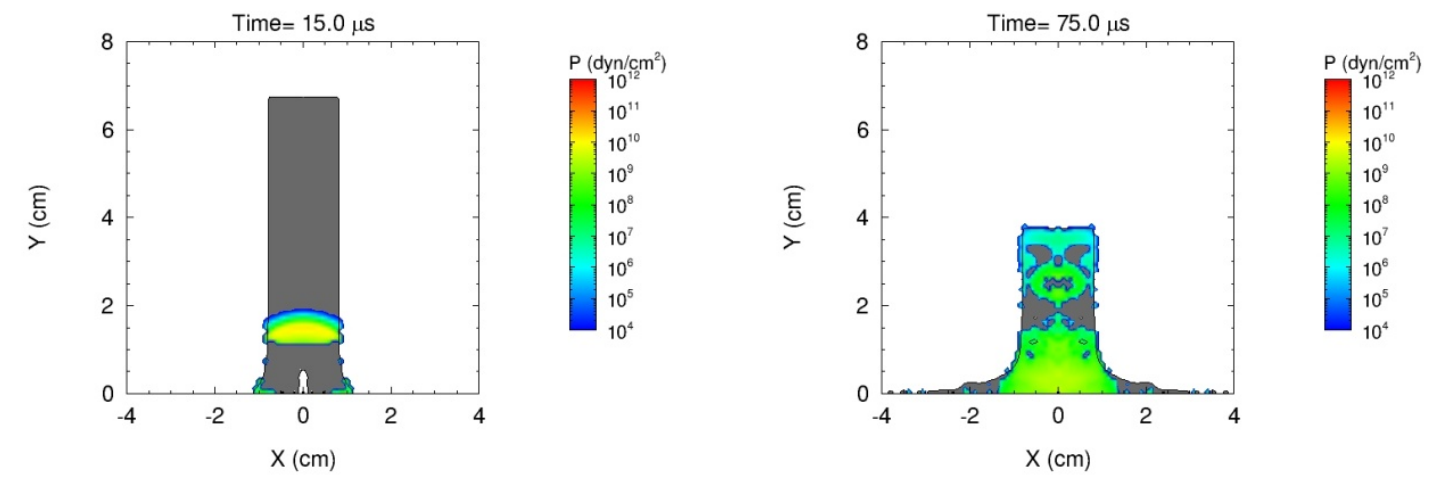

Fig. 2. Impact profiles at $500 \mathrm{~m} / \mathrm{s}$. Pressure wave is shorter and more pronounced, but otherwise the deformation behavior is similar to what is seen in Fig. 1. 
The impact velocity at which initiation first occurs in this model is $\sim 530 \mathrm{~m} / \mathrm{s}$. At this velocity, all parameters given in the HVRB model are satisfied, and the pressure wave transitions to a selfsustaining detonation wave traveling through the material. Due to the rapidly decreasing density and increasing volume, CTH abruptly quits shortly after the material finishes burning. Pressure maps for this test are shown in Figure 3.
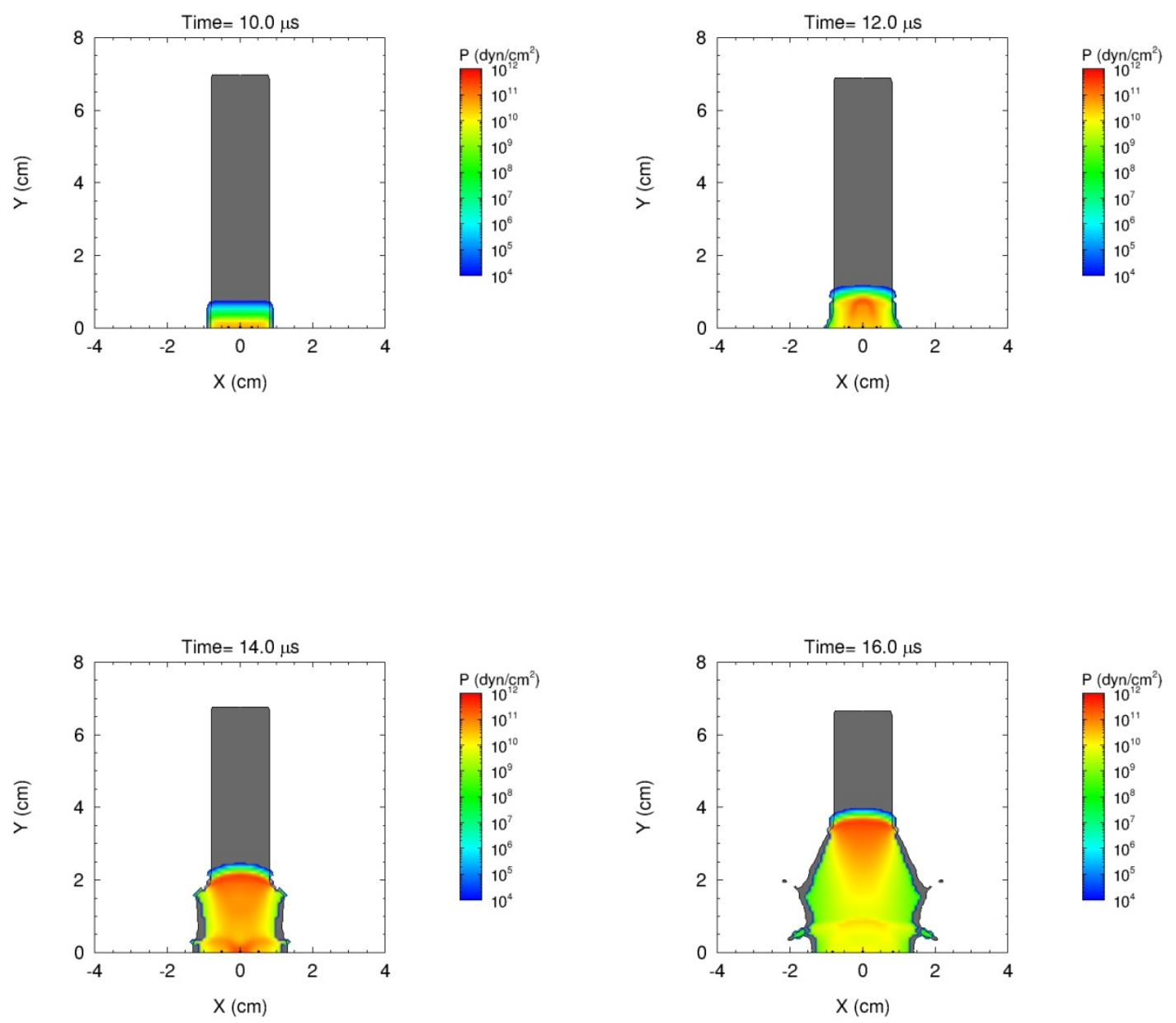

Fig. 3. Impact profiles at $530 \mathrm{~m} / \mathrm{s}$. Transition from compression wave to detonation wave is clearly visible (begins at 12 microseconds).

Additional simulations were performed with an inert tamper replacing some of the explosive, with ignition at lower velocities as the desired outcome. This was done with Teflon (a possible real-world experiment) and lead (maximum mass). Some results for an impact with a Teflon tamper are shown in Figure 4. 

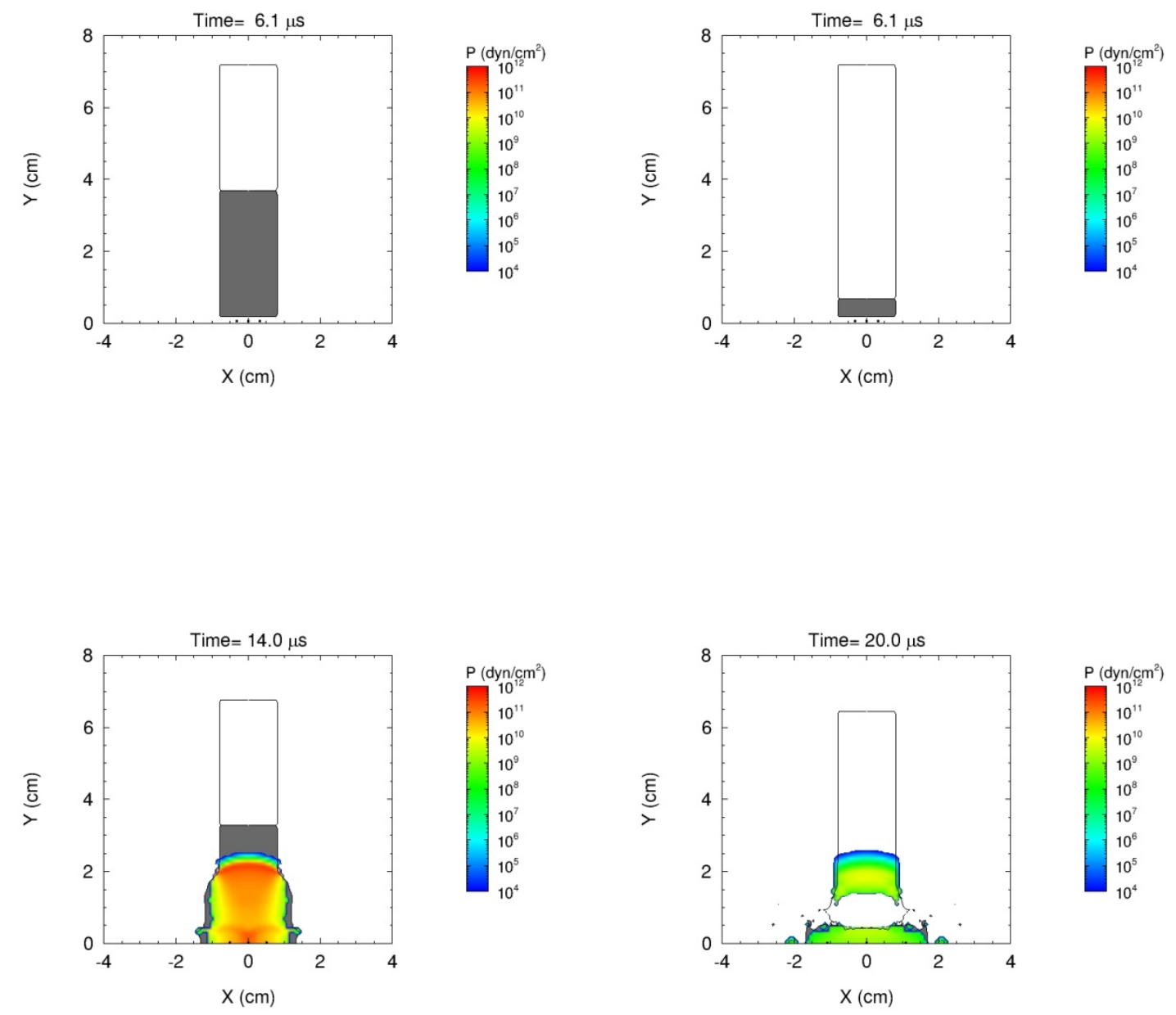

Fig. 4. Impact tests at $530 \mathrm{~m} / \mathrm{s}$ with Teflon tampers (white) behind the PBX-9501 (grey).

With the Teflon tamper, the minimum velocity for ignition remained unchanged $(530 \mathrm{~m} / \mathrm{s})$ regardless of the thickness of the tamper relative to the explosive. Furthermore, a similar configuration with a lead tamper still required a minimum impact velocity of $460 \mathrm{~m} / \mathrm{s}$ for ignition to occur. This is not a significant improvement, considering the maximum velocity for the gas gun is $\sim 220 \mathrm{~m} / \mathrm{s}$.

It is worth mentioning that this is a relatively unsophisticated model with multiple simplifications that can lead to a deviation from reality. Compressive heating of air voids in the material, fracture of HMX crystals, and friction between HMX crystals are all ignored in this model. Any of these conditions could prove favorable for ignition at lower impact velocities. 
PBXIN_Taylor.in input file with annotations.

Note: PBX_Taylor.in is another input file almost identical to this one, but it doesn't include inert materials.

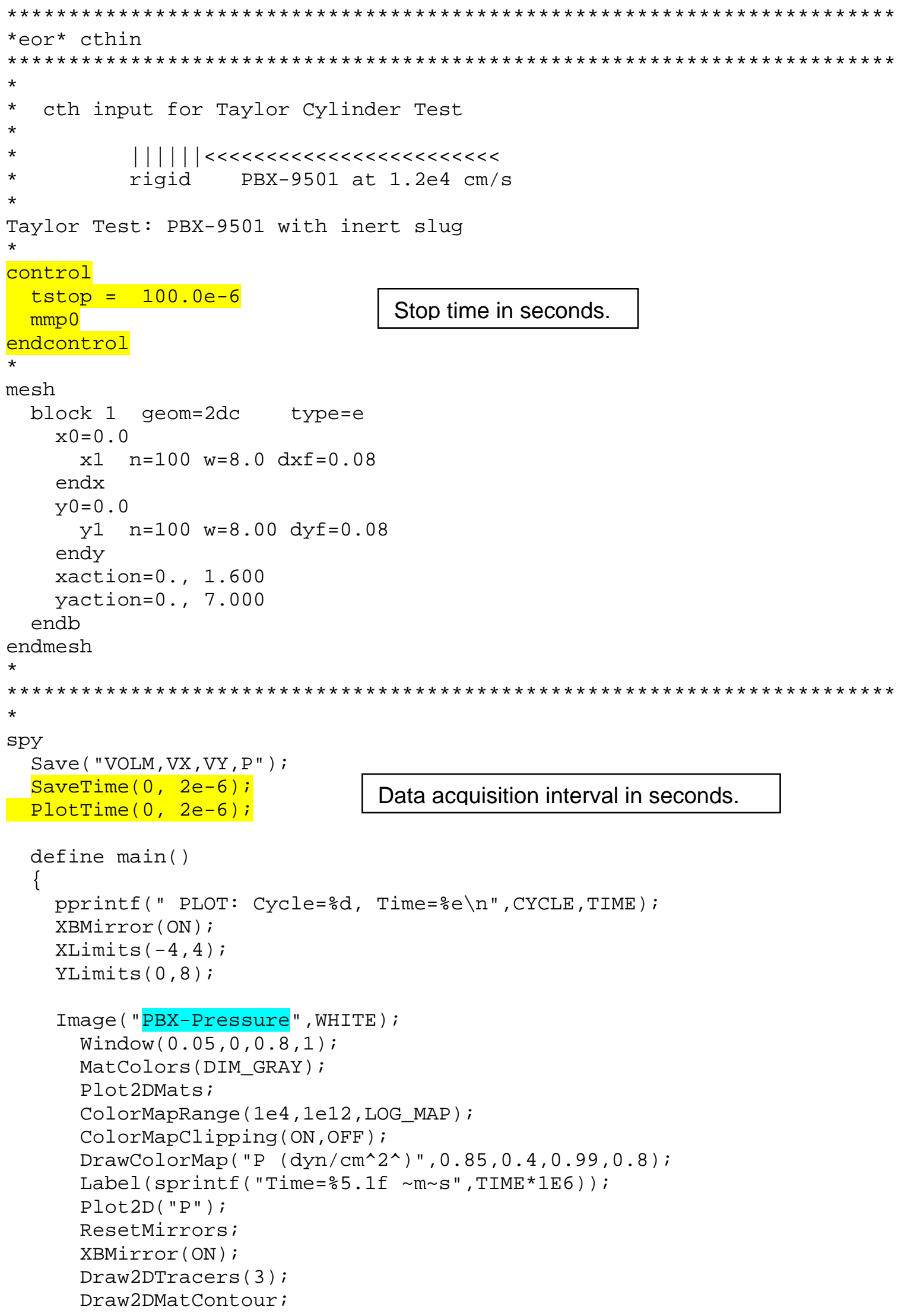




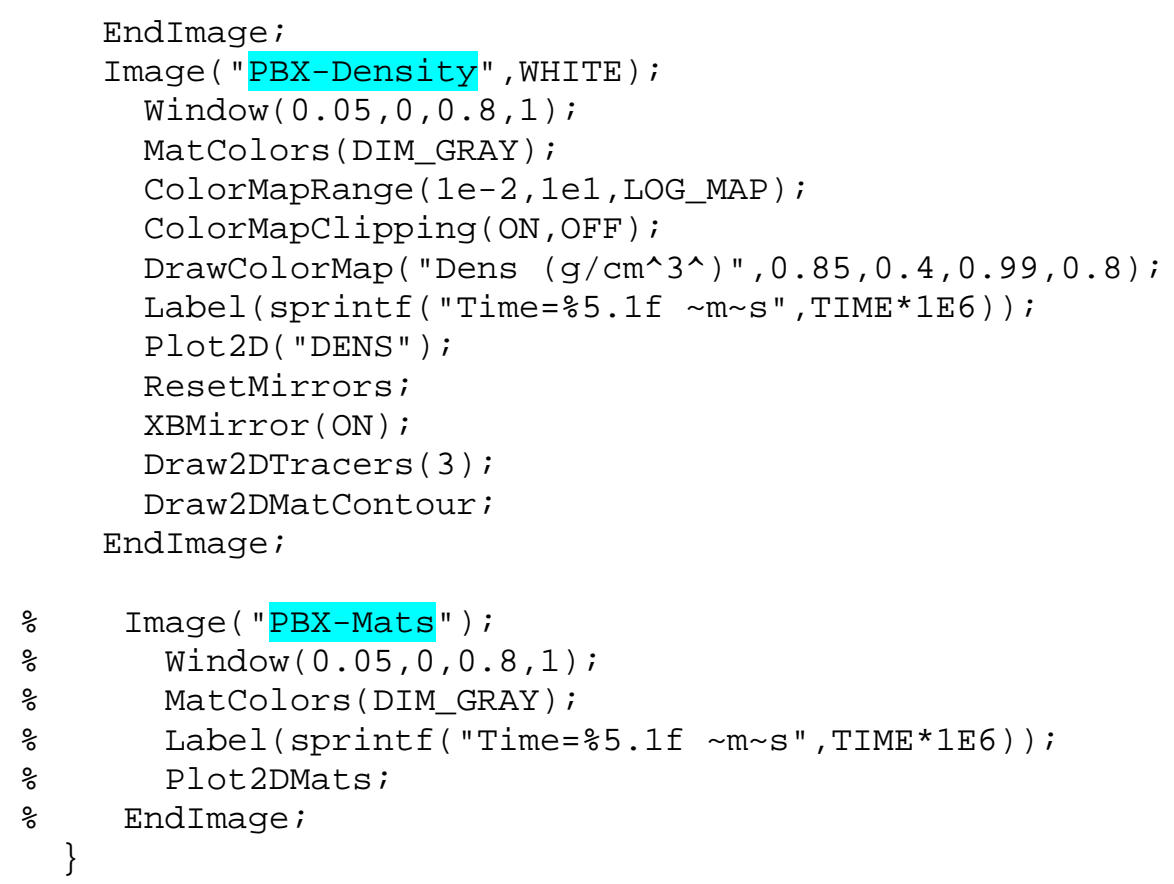




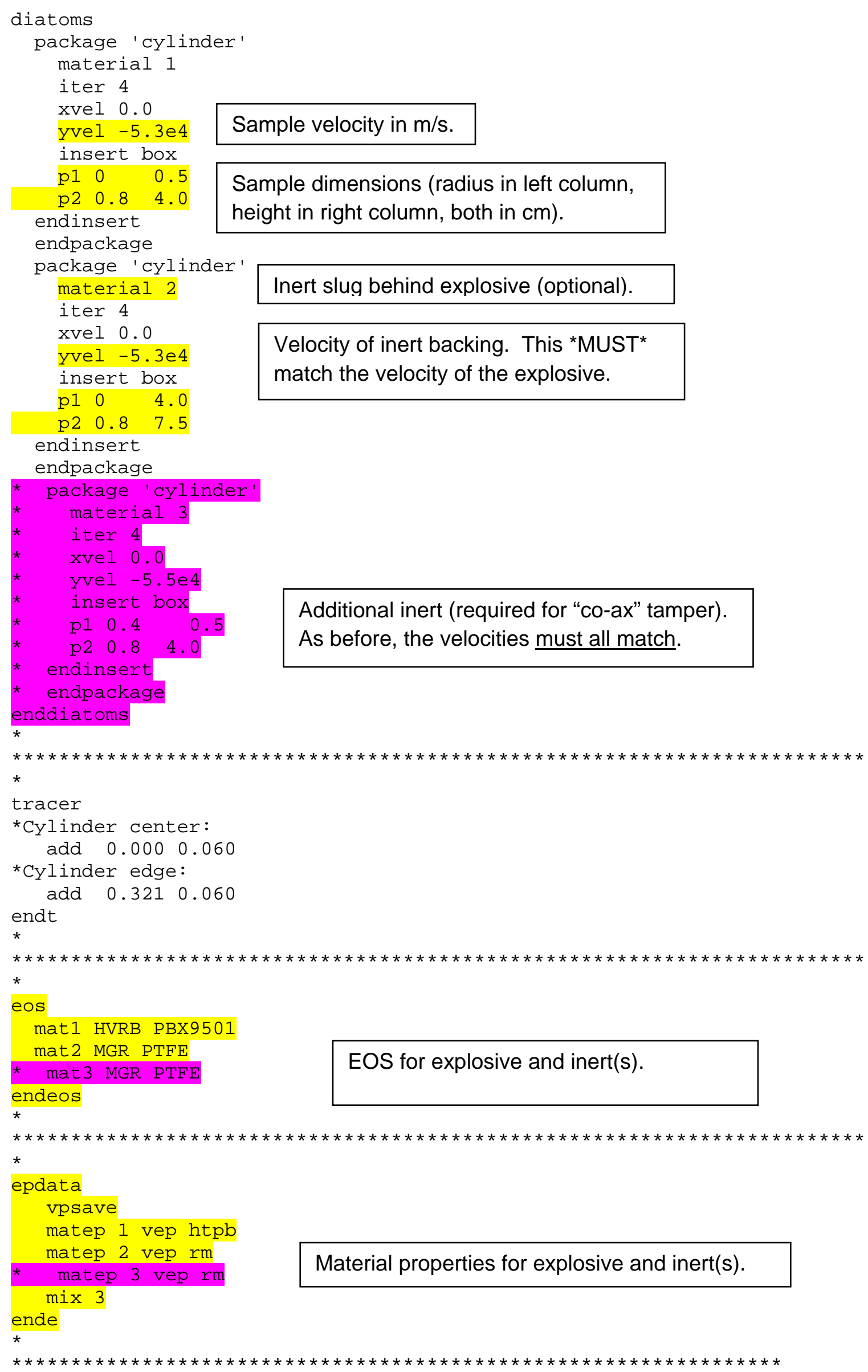


Convet

interface=high_resolution

endc

$$
\text { * }
$$

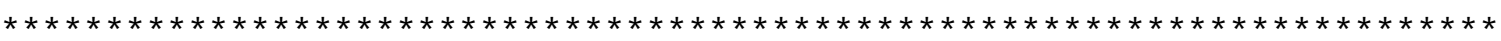

*

discard endd

CTH stops tracking material outside these limits.

*

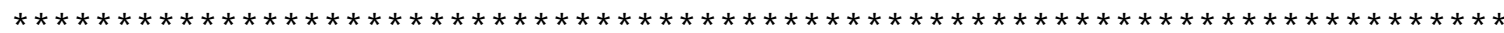

$*$

edit

shortc

$c y=0 \odot \quad, d c=1000$

ends

*

longt

time $=1 . \mathrm{e}-6, \mathrm{dt}=1.0$

endl

*

plott

time $\quad 0.0$ dtfrequency $50 \mathrm{e}-6$ endp

ende

*

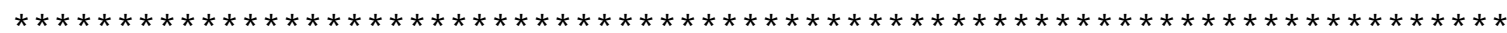

*

fracts

stress

pfrac $1=-2.0 \mathrm{e} 7$

pfmix $=-2.0 \mathrm{e} 15$

pfvoid $=-5.0 \mathrm{e} 6$

Fracture parameters for materials.

endf

*

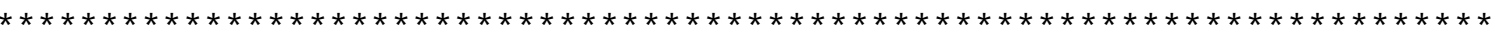

*

boundary

bhydro * rigid boundaries all around

block 1

bxbot $=0$, bxtop $=0$

bybot $=0$, bxtop $=0$

endb

endh

endb

*

$\star * * * * * * * * * * * * * * * * * * * * * * * * * * * * * * * * * * * * * * * * * * * * * * * * * * * * * * * * * * * * * * * * *$ 
This report has been reproduced directly from the best available copy. It is available electronically on the Web (http://www.doe.gov/bridge).

Copies are available for sale to U.S. Department of Energy employees and contractors from:

Office of Scientific and Technical Information

P.O. Box 62

Oak Ridge, TN 37831

(865) 576-8401

Copies are available for sale to the public from: National Technical Information Service

U.S. Department of Commerce

5285 Port Royal Road

Springfield, VA 22161

(800) 553-6847 
- Los Alamos NATIONAL LABORATORY 